\title{
José Antonio Guillén Berrendero, Juan Hernández Franco, Esther Alegre Carvajal (eds.), Ruy Gómez de Silva, príncipe de Éboli, su tiempo y su contexto, Madrid/ Frankfurt, Iberoamericana/Vervuert, 2018, 412 págs.
}

El libro Ruy Gómez de Silva, príncipe de Éboli, su tiempo y su contexto tiene su origen en un congreso que llevaba (casi) el mismo nombre y que se realizó del 20 al 22 de abril del 2016 [1], precisamente en Pastrana, ducado de Ruy Gómez de Silva (o Rui Gomes da Silva como se llamaba originalmente) y señorío principal suyo. Este libro que se divide en tres secciones con 14 autores, recoge solo las ponencias realizadas en el congreso, mientras que las comunicaciones ya se publicaron en un número monográfico de la revista Tiempos Modernos (Vo. 8, Nr. 34).

El libro constituye un gran aporte al conocimiento de la persona de Ruy Gómez pero también de su tiempo y de las circunstancias de su vida. Dada su importancia para la primera década del reinado de Felipe II, resulta difícil de comprender que haya sido investigado tan poco hasta ahora. A diferencia de otros privados o validos (a partir de Felipe III), sobre Ruy Gómez existe una sola biografía, publicada en 1995 por James Boyden. Además, ha quedado tradicionalmente en la sombra de su esposa, la princesa de Éboli que cuenta con una amplia bibliografía, clásica y actual. También ha sido figura habitual en obras teatrales, novelas e incluso de cine y televisión, por lo que también fuera del ámbito académico resulta mucho más conocida.

En cuanto al ámbito académico, este libro contribuirá a remediar esta carencia. A modo introductorio, Jaime Contreras nos introduce en el mundo de la nobleza, lo que significaba ser noble y las virtudes que se esperaba de sus integrantes. En este sentido también refiere los discursos de superioridad moral que pretendía tener la nobleza sobre los comunes. En este contexto ubica finalmente a Ruy Gómez y su linaje y lo caracteriza como segundona y además proveniente de otro reino. Deja claro, por lo tanto, que a priori las posibilidades de Ruy Gómez de realizar una gran carrera nobiliaria no eran muy elevadas.

A continuación, el primer bloque temático se intitula Interpretaciones sobre su papel: las huellas. Las cuatro contribuciones logran abarcar aspectos concretos de la vida y actuación de Ruy Gómez pero también nos hacen entender el contexto en el que se desarrollan. José Antonio Guillén Berrendero nos muestra el Ruy Gómez

José Antonio Guillén Berrendero, Juan Hernández Franco, Esther Alegre Carvajal (eds.),

Ruy Gómez de Silva, príncipe de Éboli, su tiempo y su contexto, Madrid/Frankfurt, Iberoamericana/Vervuert, 2018,412 págs. Matthias Gloël.

Autoctonía. Revista de Ciencias Sociales e Historia, Vol. III, Nº1, Enero-Junio 2019, 89-92 
cortesano, líder de la facción ebolista y privado del rey. Concluye que constituye un nuevo tipo de político, un arquetipo del que habría varios émulos más adelante.

Santiago Martínez Hernández realiza una comparación entre Ruy Gómez y Cristóbal de Moura, los dos grandes privados portugueses que tuvo Felipe II, al principio y al final de su reinado. Si bien la presencia de castellanos y portugueses en el reino del otro era algo frecuente, mucho menos usual era que uno de ellos llegase a una posición cortesana tan destacada como Ruy Gómez y Cristóbal de Moura. Ambos supieron aprovechar su posición para surgir de su situación de segundón sirviendo en séquitos principescos, convirtiéndose en señores territoriales con vasallos. Si bien el autor destaca unos hitos parecidos que llevaron a ambos a la privanza del rey, concluye que la carrera de Moura terminó siendo más exitosa al nunca perder la confianza del monarca y por tener un papel mucho más activo en el ámbito político.

Francisco Precioso Izquierdo analiza la imagen de Ruy Gómez en las crónicas sobre el reinado de Felipe II que se publicaron tras su muerte en el siglo XVII. El autor logra mostrar que dicha imagen (y también la del monarca) se suele ver afectada por las intenciones políticas de los respectivos autores.

Esther Alegre Carvajal dedica su texto al territorio de Pastrana que se convertiría en ducado en 1572 con Ruy Gómez como su primer titular. Evidencia los vínculos que tenía Pastrana de antes con la familia de su esposa Ana de Mendoza y cómo fue el largo proceso de adquisición por parte de Ruy Gómez, cuyo proceso duró por lo menos una década completa (1559-1569). Finalmente, la autora muestra las grandes medidas que emplea relanzar el comercio de su nuevo territorio, incorporando sobre todo moriscos expulsados de Andalucía, expertos en la industria sedera.

El segundo apartado lleva el título Familia, Servicio y Territorio: el Poder. Los primeros dos contribuciones muestran como aportar al conocimiento acerca de un personaje histórico, sin que el texto esté centrado en él. Ana Isabel Buescu, por una parte, explica los antecedentes familiares de Ruy Gómez, tanto paternos como maternos. Se trata de dos familias que desde el siglo anterior están ligados a la corona portuguesa y la autora muestra los sucesivos enlaces matrimoniales en Castilla y Portugal condicionan su suerte hasta el momento que el segundogénito Ruy Gómez de Silva entra como paje al servicio de la infanta y futura emperatriz Isabel.

El texto de Félix Labrador Arroyo, por otra parte, de cierta forma continúa donde termina el anterior. El autor evidencia que había muchos portugueses en condiciones similares como Ruy Gómez al servicio de reinas e infantas castellanas. Muestra, además, que a pesar de los intentos del partido castellanista, encabezado por Francisco de los Cobos, de alejar a estos portugueses de los puestos de influencia, éstos logran sentar la base del partido ebolista. Lo anterior lo logran juntos con familias castellanas que no pertenecían al partido castellanista y con las que muchos de los portugueses contraían matrimonio.

Francisco Fernández Izquierdo explica el mundo de los señoríos castellanos en la Edad Moderna en el que Ruy Gómez se terminaría insertando. En este sentido, el autor documenta las adquisiciones exitosas como Zorita y las que se le resistían como Almonacid concluyendo que aunque no logró realizar todas sus pretensiones territoriales, Ruy Gómez fue capaz de crear un señorío suficientemente sólido para poderse mantener durante varias generaciones. 
Miguel Gómez Vozmediano caracteriza el trabajo de investigación en archivos nobiliarios para entrar a continuación en el caso del archivo de los duques de Pastrana. Señala la división interna entre los documentos de Ruy Gómez y de los de su esposa, lo cual indica que era una práctica habitual en archivos de la nobleza. Documenta, además, la conservación de documentos claves del ámbito familiar e incluso del testamento del propio Ruy Gómez.

La tercera parte del libro se intitula Ruy Gómez, contextos, discursos y represntaciones y trata de temas más bien artísticos, los cuales, sin embargo, no son de menor importancia que los previos. La excepción constituye el primer texto de Lina Scalisi, el cual está dedicado a la Sicilia después de la batalla de Lepanto con la presencia del triunfador Don Juan de Austria y el presidente del reino Carlos de Aragón, el duque de Terranova.. Ruy Gómez está apenas presente directamente en el testo, sin embargo, es clave para la comunicación del duque con la corte. De esta forma, el autor muestra con el caso de Carlos de Aragón la importancia de Ruy Gómez tenían para las carreras de otros nobles.

Germán Labrador López de Azcona, por su parte, nos lleva al mundo de los festejos cortesanos y la importancia que tenían dentro de la vida de la corte. Se enfoca concretamente en los bailes con máscara y más específicamente en las festividades de la corte en Bruselas en 1550, en el marco del viaje del entonces príncipe Felipe a los Países Bajos. Se apoya principalmente en el relato de Calvete de Estrella sobre este viaje del futuro rey.

Iván Martín Cerezo en coautoría con Juan Carlos Gómez Alonso tratan en su texto del arte de la retórica como parte del tradicional ars dictaminis, el cual fue la base de la retórica epistolar de los siglos XVI y XVII. A continuación, los autores se dedican a las cartas de Ruy Gómez, principalmente hacia Juan de Escobedo aunque también a otros, caracterizándolas un tanto automatizadas y esquemáticas.

Macarena Moralejo Ortega se ocupa de la colección artística del propio Ruy Gómez. Destaca su gran compresión de temas de arquitectura y muestra cómo usaba sus redes y contactos diplomáticos también para sus intereses personales, realizando compras, ventas e intercambios de objetos preciosos.

Finalmente, a modo de clausura, Trevor Dadson se dedica al legado político de Ruy Gómez, primero en Antonio Pérez y después en el siglo $\mathrm{XVII}$ en el duque de Lerma y especialmente en su hijo segundogénito Diego de Silva y Mendoza. Llama la atención que este hijo que sería conde de Salinas y duque de Franvila emula hasta cierto punto la carrera de su padre que también había sido segundogénito. Persona de confianza del duque de Lerma quedó mucho tiempo a cargo de los asuntos portugueses, primer en la corte y más tarde en el propio reino. Al igual que su padre defiende una política de paz y de diálogo, sin embargo, concluye el autor, la monarquía no habría sabido aprovechar a estos dos personajes extraordinarios, cuyas visiones fueron ignoradas a beneficio de otras $\mathrm{m}$ 'sa beligerantes y belicistas.

En suma, el libro resulta importante y necesario para entender mejor las distintas facetas de Ruy Gómez y su época, ya que los distintos autores logran mostrar cómo se movía en la corte del príncipe primero y después como privado y señor territorial en la Castilla y Europa moderna. 


\section{NOTA}

1. Existe un resumen del congreso, publicado en Cuadernos de Historia Moderna, 41 (2), 2016, pp. 612-614. 